\title{
LA CAÍDA DE LOS REFERENTES EN EL MUNDO CONTEMPORÁNEO: ANÁLISIS DEL CONCEPTO UNARIO EN DANY ROBERT-DUFOUR
}

\section{THE FALL OF THE REFERENTS IN THE CONTEMPORARY WORLD: ANALYSIS OF THE UNARY CONCEPT IN DANY ROBERT-DUFOUR}

\author{
Romero Ramírez, Israel Alejandro ${ }^{1}$
}

\begin{abstract}
Resumen
El siguiente trabajo tiene como finalidad abordar el concepto que ha trabajado el filósofo francés Dany Robert-Dufour, en su libro Locura y democracia: lo unario. Este concepto tiene su referente tanto en la filosofía como en el psicoanálisis. La propuesta de Dufour es que las sociedades contemporáneas experimentan la caída de referentes, los cuales habían organizado la vida subjetiva en distintos momentos históricos, como Dios, el Estado y la Razón. Estos referentes, para el filósofo francés, organizaban la vida subjetiva de individuos y les otorgaba sentido a su vida cotidiana. Sin embargo, la caída de los referentes invierte los valores y lleva a una inminente pérdida de sentido. Esta pérdida de sentido se traduce en una imposibilidad para el sujeto de moverse en su entorno y en todo aquello que le es familiar. Como consecuencia, la relación entre la pérdida de sentido, junto a la caída de los referentes, nos muestra Dufour, es lo que nos lleva a una nueva forma de locura que gira en torno a lo unario.
\end{abstract}

Palabras clave: Unario, facticidad, inconsciente, referente, ontología.

\begin{abstract}
This paperwork has, as Main objective, approach concept of the French philosopher Dany Robert-Dufour who has worked in his book Madness and democracy: Unary. This concept have their reference as in philosophy as in psychoanalysis. The Dufour proposal is that the contemporary societies experience the fall of referent, which has organized a subjective life in many different historical ages, as God, State and Reason. Those references, for the French philosopher organized the individual subjective and gave sense to their regular life. However the fall of the references switched the values and the common sense got lost. This lack of sense is traduced in impossibility for de subjective to move around him and all his environment.
\end{abstract}

${ }^{1}$ Universidad de Guadalajara, México. Email: israel.alejandro.rr@gmail.com

ISSN: 2007-1833 
As consequence, the relationship between the lack of sense and the fall of references, Dufour show us, is the thing that take us to a new way of madness that moves around the unary Keywords: Unary, facticity, unconscious, referent, ontology.

\section{Primer momento de la auto-referencia: El encuentro de la razón consigo misma.}

La filosofía de Descartes es una filosofía que busca la verdad, pero ya no en el sentido clásico. En los griegos era una actitud del hombre hacia las cosas, tal y como lo había pensado Aristóteles al inicio de la Metafísica: "Todos los hombres por naturaleza desean saber. Señal de ello es el amor a las sensaciones". (Aristóteles, 2007, p. 65) Como también lo escribía Descartes al inicio de las Reglas para la dirección del espíritu: “...no hace falta cohibir los espíritus con limitación alguna, puesto que el conocimiento de una verdad no nos aparta del descubrimiento de otra...". (Descartes, 2014a, p. 3) El tema de la verdad y el camino que recorremos es el tema fundamental en Descartes. El método es el único camino a la verdad; y sabemos muy bien que se refiere a la matemática, ya que solamente ella puede otorgarnos un modelo universal y valido del mundo. Sin embargo, el método solo puede explicarse si se atiende a su origen que es la subjetividad. Descartes es el primero en plantearse que el método debe de ir acompañado de una explicación que nos diga cómo pensamos. El paso de la subjetividad a la objetividad que nos proporciona el paso a la ciencia, será un tema fundamental en su pensamiento. Este mismo recorrido lo va a desarrollar Kant con el paso del tiempo, claro está que desde otras coordenadas. Pero debemos decir que Descartes es el primero en partir de la subjetividad (Intuición). Aunque solamente la tome en un aspecto meramente formal y ese es precisamente la crítica que le hace Husserl y después Heidegger: "Una de las primeras tareas de la analítica consistirá en hacer ver que si se pretende partir de un yo o sujeto inmediatamente dado, se yerra en forma radical el contenido fenoménico del Dasein". (Heidegger, 2009, p. 67) Lo que nos interesa de la cita de Heidegger, es que apunta su reflexión a un sujeto dado, y también podemos agregar abstracto. 
A final de cuentas, para Descartes, la ciencia es la única que puede mostrar un conocimiento claro y evidente, pero como hemos mencionado arriba, la ciencia que parte solo de un método deductivo. El fundamento ontológico del cual parte el cartesianismo es de la intuición psicológica: Cogito ergo sum. Intuición que nos regala la primera certeza que es la diferencia entre el pensamiento y lo pensado. Certeza que nos muestra la autoreferencia, la cual va a inaugurar una nueva forma de plantearse problemas y va a construir, a su vez, lo que conocemos como el sujeto de la ciencia. Sujeto que ya estaba implícito en Kepler y Galileo, pero que Descartes nos sorprende al hacer preguntas de manera distinta, aparte que comienza una manera distinta también de escribir, con un estilo simple y claro, que busca ser leído no solamente por el erudito. Esto podemos observarlo en la siguiente cita, en la cual nos muestra su descubrimiento: "...yo era una sustancia cuya esencia y naturaleza toda es pensar, y que no necesita, para ser, de lugar alguno, ni depende de cosa alguna material; de suerte que este yo, es decir, el alma por la cual yo soy lo que soy, es enteramente distinta al cuerpo...". (Descartes, 2014b, p. 124)

A pesar de que la idea de Dios no desaparezca del plano de la filosofía cartesiana, lo que sí podemos observar es que ya no es el único plano, o al menos el más importante, ya que aparece el fundamento que Descartes necesitaba para poder referir el problema del conocimiento al hombre mismo. Así, en su libro Las pasiones del alma, Descartes se autoriza para explicar un sinfín de fenómenos que tienen que ver tanto con el cuerpo como con el alma. Nos dice que es un error grave referir el calor que sentimos en nuestro cuerpo al alma, ya que dicho calor proviene del corazón y la sangre: “... que el alma solo se ausenta, cuando uno muere, a causa de que cesa este calor y de que se corrompen los órganos que sirven para mover el cuerpo". (Descartes, 2014c, p. 157) Como se puede ver, Descartes se sirve más de la deducción y un poco menos de la observación que de una reflexión teológica, que aquí es ausente. Sabemos que el tema de Dios aparecerá en otros momentos y que podría generar algún tipo de controversia; pero no debemos detenernos en estos puntos, ya que el pensamiento de Descartes, a mi parecer, debe ser leído como una filosofía de transición. 
Podríamos ver los efectos de la filosofía cartesiana, en un plano social, en el de una ganancia en el tema de la libertad individual, ${ }^{1}$ goce que no se tenía en el medioevo, pues la idea de Dios inundaba casi todo el campo de reflexión y eso se traducía en la hegemonía moral de una institución, como es la religiosa. Erich Fromm lo muestra muy bien en una cita de su libro El miedo a la libertad: La sociedad medieval no despojaba al individuo de su libertad, porque el individuo no existía todavía; el hombre estaba aún conectado con el mundo por medio de sus vínculos primarios. (Fromm, 1985, p. 65) El hombre medieval dedicaba gran parte de su vida, si no es que toda, al tema de la salvación. El hombre moderno busca ante todo reafirmarse en la tierra.

\section{Segundo momento de la auto-referencia: Kant y la ilustración.}

La mayoría de las veces erramos en entender la llustración como un periodo histórico, pero el filósofo alemán lo entendía más como un proceso que como un suceso histórico. Incluso en su idea de historia introduce una metafísica en la que la historia persigue un fin, que no es otra cosa que la idea misma de maduración: "Cualquiera sea el concepto que se tenga sobre la libertad de la voluntad, desde el punto de vista metafísico, las manifestaciones fenoménicas de la misma, es decir, las acciones humanas, están determinadas por leyes universales de la Naturaleza, tanto como cualquier otro acontecimiento natural". (Kant, 2004, p. 17) Desde esta postura, el hombre al reflexionar sobre su largo camino dentro de la historia, no podría, sino reconocer que al estar dentro de un proceso, este lo lleva a una autonomía que el hombre nunca había experimentado; no podría desde esta tesis sino sentir la libertad que los antiguos ni siquiera conocieron. La racionalidad le da al hombre urbano la capacidad de discernir y de entender que la vida dentro de un Estado no es ninguna imposición, sino todo lo contrario: es la única posibilidad de experimentar el progreso y la idea de un fin en común. Pero, entonces,

\footnotetext{
${ }^{1}$ Es importante mencionar que este cambio de debió en gran medida a los cambios económicos y sociales que surgieron desde el siglo XIV. La aparición de los mercaderes y de población que emigro fue generando cambios que van a ir desmontando al sistema feudal.
} 
¿qué significan las guerras que hasta ese entonces habían aparecido? Kant parte del principio de que el progreso es de menos a más. Incluso da cuenta que no hay un estado de libertad, sino que la libertad seguramente la conocerían sólo las generaciones venideras. El concepto de progreso le permite a Kant entender el proyecto de la llustración como un movimiento que enlaza a una generación con otra sin que necesariamente las personas entienden la finalidad a la que son llevados: "La razón de una criatura consiste en la facultad de ampliar las reglas e intenciones del uso de todas las fuerzas más allá del instinto natural, y en sus proyectos no conoce límite alguno". (Kant, 2004, p. 19) El progreso está acompañado de los logros científicos, pero también de una racionalidad moral capaz de alejarse de las creencias y costumbres que limitan a los hombres y que los mantendría en su niñez, como los llama Kant. Aunque el filósofo alemán, por un momento, pondrá en duda que Europa esté en ese paraíso: "El arte y la ciencia nos han cultivado en alto grado. Con respecto a las buenas maneras y al decoro social, estamos civilizados hasta la saturación. Pero nos falta mucha para podernos considerar moralizados. La idea de la moralidad pertenece también a la cultura [Kultur]; pero el uso de la misma constituye la civilización [Zivilisierung] cuando solo desemboca en la apariencia ética de un amor al honor y a la decencia exterior". (Kant, 2004, p. 27) En esta cita, hace una distinción profunda entre progreso científico y ética; creo que esa diferencia es uno de los grandes males que han aquejado a Europa -por lo menos hasta las guerras mundiales-. Kant entrevé que este ideal está lejos de Europa. Pues las relaciones que establece Kant en su filosofía política no se limitan para nada a la relación entre Estado y ciudadano, sino a la relación de un Estado con otro. En su libro La paz perpetua, Kant, a mi manera de ver, será en donde expondrá con mayor claridad el gran proyecto de Europa: la creación de una Federación que haga posible la paz.

Su idea de racionalidad es práctica y no obedece a una dimensión abstracta. De hecho: Qué es la ilustración fue publicada en un periódico, lo que nos hace ver que la idea de Kant era la de una visión de tipo cosmopolita, pues tampoco se limitaba su reflexión a un pueblo en particular: "El mayor problema de la especie humana, a cuya solución la Naturaleza constriñe al hombre, es el del establecimiento de una sociedad civil que administre el derecho de modo universal". (Kant, 2004, p. 22) Kant pudo entender 
que una racionalidad en abstracto no tendría a la larga ningún fin práctico y no conduciría a resolver los problemas de Europa. La idea de civilización entendida por conocimiento acumulado, carece de sentido si no hay una ética de fondo que provenga del espíritu de los propios individuos, y que a través de ésta puedan ayudarse a dirimir sus conflictos. Aquello que tendría que emerger de la sociedad civil, no es otra cosa que el Estado de derecho. A la manera de Platón, está pensando en la relación Estado- ciudadano. Lo que quiero esclarecer con esto es que sujetos racionales crearían entre todos un estado racional. Desde esta perspectiva, el Estado no nacería como algo distinto a los individuos ni tampoco este sería visto como si tuviera una naturaleza distinta, y la cual los llevaría a verlo como algo impositivo y ajeno a los ciudadanos (tal y como describe al Estado, Franz Kafka). Es muy importante este punto para nuestro propósito: la racionalidad no surge del gobierno, sino en los individuos, en el paso del estado natural al de sociedad civil. De ese paso tendría que nacer el estado de derecho. Pero también Kant pone la relación con el otro como un punto importante. Lo que él llama la acción comunicativa no surge de quienes gobiernan, sino que emerge de los individuos, de ellos surge esa responsabilidad. De no entenderlo así, volveríamos a conjeturar algo abstracto que no sabríamos entender: "La comunicación, o si se prefiere la acción comunicativa, queda ligada al impulso, por decirlo así, de encontrar al otro, de formar comunicación con él; en ese sentido, aun dentro de la Rechtslehre, tal idea ya no ingresa precisamente dentro del discurso sistémico de la sociedad civil, sino dentro de lo que podríamos llamar su discurso comunicativo" (Hernández, 1991, p. 14).

Podemos ver que en ambos autores, la auto-referencia, aparece como principio filosófico. El concepto de autonomía es fundamental para entender el pensamiento moderno. Todo aquel que no pudiera ejercer su autonomía estaría condenado a la inmadurez kantiana, o en su defecto, podríamos allanar el camino a la figura del loco. Sin embargo, si la modernidad y con ello su proyecto fueron un mito, no es un asunto en el que nos debamos detener, sino más bien en ver los efectos subjetivos que esto ha traído a nuestro tiempo. Dany Robert-Dufour es un filósofo que ha estudiado los efectos subjetivos de la auto-referencia, pero sobre todo ha analizado lo unario, concepto que es 
parte fundamental de su trabajo. Pero antes de hablar de este concepto, es importante revisar los efectos subjetivos que ha traído al mundo contemporáneo; por lo menos anunciar algunos, antes de que pasemos al tema de la facticidad, para abordar lo que llamaremos la cotidianidad desde Heidegger.

Fromm había planteado que si el hombre moderno había conseguido autonomía, había perdido en consecuencia la pertenencia a la tierra, que era algo que caracterizaba al hombre de la Edad Media. Lo que aparecería en el hombre moderno sería la soledad (desarraigado). Pero veamos que nos dice Dany Robert Dufour: "La cultura y la democracia de masa individualizan: eliminan las añejas solidaridades y hostilidades para no dejar más que individuos solos consigo mismos" (Dufour, 2002, p. 37). Precisamente porque cualquier actividad implicaba un contacto con los otros, cosa que ahora ya no es necesaria. Muchas de nuestras actividades pueden hacerse de manera que no necesitemos de los otros. Así podemos hacer una llamada, por ejemplo, a alguna empresa telefónica para resolver un problema y podemos pasarnos algún tiempo sin que tengamos contacto con una voz humana, sino con una grabación. Muchas de las relaciones que en nuestro tiempo tenemos se reducen en su gran mayoría a relaciones utilitarias. Por tales cosas, cuando uno analiza el gran proyecto de Descartes o Kant, uno no puede más que pensar en que algo salió mal, o que en realidad fue solamente un pensamiento que se apoyó en un ideal del hombre.

\section{La facticidad: nuestro existir propio en cada ocasión}

La categoría de Heidegger es de nuestro interés para entender, en el marco del problema que queremos desentrañar, qué queremos decir con la palabra cotidianidad. Para esto, la obra del filósofo alemán nos ayudará a entender y dará luz a nuestro trabajo. Para Heidegger, ambas auto-referencias, la de Descartes y Kant, nos llevan al ocultamiento del ser. Nos dirá Heidegger que, poco dicen sobre el ser: "Dirigiéndose hacia... y aprehendiendo algo, el Dasein no sale de su esfera interna, en la que estaría 
primeramente encapsulado, sino que, por su modo primario de ser, ya está siempre fuera, junto a un ente que comparece en el mundo ya descubierto cada vez". (Heidegger, 2009, p. 83) Pensemos que tanto a Descartes como a Kant parten del supuesto de que hay una razón ubicada en un interior, y que se trataría de analizar a esa razón. A Heidegger no le interesa nada de esto en absoluto. Sus problemas no son epistemológicos, sino ontológicos.

Cuando Heidegger, en el capítulo segundo de Ser y tiempo nos habla de su categoría existencial estar en, a lo que se refiere es a que en nuestra posición de entes, compartimos el mismo estar en que cualquier otro ente en relación a un lugar. Pero cuando hablamos del ser, ya estamos hablando de algo muy distinto. El ser implica habitar, yo soy....implica una relación: estoy haciendo mi cama, estoy cocinando, etc. Cuando digo "estoy cocinando", lo que quiero dar a entender es que los objetos con los que me encuentro, me son todos familiares, o por lo menos sé qué voy a hacer con ellos. Heidegger va a utilizar la palabra familiarizado, y para estarlo es necesario que el Dasein lo descubra; quiero decir, que descubra al objeto. Cuando los objetos me son familiares es porque me son accesibles, y es que con ellos hago algo sin que necesite del juicio para poder hacer algo con ellos; simplemente me veo y me ven haciendo algo, por ejemplo: cocinar.

Por lo tanto, facticidad implica un saberme mover en el mundo, en tanto que ese mundo me es familiar. La familiaridad es que estoy siempre ocupado con aquellos objetos con los que siempre trabajo o hago cosas. Como hemos leído, aunque la propuesta de cada uno de los filósofos de los que hemos hablado pueda distar en unos menos y en otros totalmente radical, los tres parten de un hombre que comprende e interpreta su mundo. Claro que la idea de comprender e interpretar en cada uno de los filósofos es diferente, y podríamos detenernos en revisar cada uno de sus argumentos. Pero lo importante para nuestra empresa es que la filosofía, hasta este momento, no toma en cuenta la posibilidad de una no comprensión del mundo, lo que nos llevaría a pensar la irracionalidad. Es entonces que nos vemos obligados a trabajar la propuesta de Jacques Lacan. 


\section{El "no comprender" como imperativo en el análisis}

Jacques Lacan dicta una conferencia en Sainte Anne, a la comunidad psiquiátrica en Francia, el 10 de Noviembre de 1967. En dicha conferencia se pregunta sobre lo que le está reservado al psicoanálisis. Inicia reprochando que no haya conciencia de masa, sino efectos de masa. Pero querer ver los efectos de masa bajo la idea de una clave, nos lleva inevitablemente a una clínica, no de la escucha, sino de la observación; desde este punto, a una fenomenología. Una fenomenología nos llevaría a pensar la debilidad mental, personalidades desintegradas, minusvalía mental, etc., a través de una caracterología. Pero también Lacan critica la idea de comprensión, en el sentido que el otro pueda aparecer como transparente y por tanto comprensible: "iel psicoanálisis consiste en descubrir que no somos transparentes a nosotros mismos! Entonces, ¿por qué los otros se nos volverían así?"(Lacan, 2018, p.6) Con esto, Lacan parte no de la idea del sabio en una interpretación errónea que se tendría de la filosofía socrática, sino del ignorar como principio de toda búsqueda por saber. La clínica de Lacan no parte de un deseo de goce, que es la clínica freudiana; sino que nace del Deseo de saber, que es el principio de Sócrates. Pero no se puede partir del Deseo de saber ya sabiendo, que es el punto más crítico de toda la psicopatología. Adelantarse a comprender nos lleva a un no comprender. Partir de la no comprensión nos permite atisbar que puede aparecer algo nuevo y que no necesariamente tenemos que decir que lo hemos comprendido. En este caso, un modo de lazo distinto que, por ejemplo, en México aparece a la luz de una nueva forma de violencia, una violencia que tendríamos que decir que aparece como incomprensible de momento. Violencia que tiene efectos subjetivos que hacen que los sujetos no experimenten la familiaridad de Heidegger, o que no nos explica la razón de Descartes y Kant. Lacan también apela a que la locura no se debe atender a partir de la afectividad, que sería una clara crítica de nueva cuenta a la psicología, sino que el psicoanálisis debe atender a la palabra de quien dice algo, y que no debemos suponer que esa palabra tendría que tener sentido. El alienista renuncia a la escucha de lo que 
diga el loco: ¡Vaya, si usted no dice cosas con sentido, para qué habría que escuchar lo que usted dice! Lacan no hace una equivalencia entre lenguaje y pensamiento, como sí lo hace Descartes. El psicoanálisis parte al revés del pensamiento cartesiano, nos lo dice Lacan en su conferencia La ciencia y la verdad: "allí donde ello era, allí como sujeto debo advenir yo" (Lacan, 2003, p. 843). Se suele decir: esos pensamientos no son míos, yo no quise decir tal cosa. Cuando se dice que el inconsciente habla, es poner las cosas en otro lugar, es indicar que yo no todo hablo, que no todo lo que digo tendría por qué tener sentido. Ahora bien, la escucha puede generar sentido, y es que ponernos a escuchar nos lleva a la posibilidad de saber, sin que haya una promesa de comprensión. Por eso Lacan se opone a que no haya un tiempo cronológico para comprender, es por eso que ese tiempo no opera en su modo de hacer clínica. Toda escucha está sometida a la ambigüedad de la palabra. Para Lacan es ilusoria la autorreferencia yo soy yo, sino siempre un yo soy otro. Pero el yo, recordemos, es imagen siempre engañosa y alienada: ¿Cómo soy yo? Le preguntamos en ocasiones al semejante. Mi mismidad me viene del otro, siempre alienada. Pero quién responde a la pregunta ¿cómo soy yo? Sabemos que no es el otro (semejante) quien la responde, sino el Otro, con mayúscula. ${ }^{2}$ El Otro, causa de mi Deseo. No hay ser sin relación trágica de ambigüedad que impone el lenguaje. Toda idea de sentido queda cuestionada de entrada. Cuando alguien se encuentra en análisis y habla, se puede ver cómo todo sentido que aparece es siempre para él engañoso, movedizo, lugar inseguro: será acaso esto o puede ser que quiso decir esto otro, no lo entiendo. Por eso es que el psicoanálisis no parte del sentido, sino de leer el sinsentido.

Con lo que hemos puntualizado arriba, podemos observar que Lacan se aleja de manera radical de toda explicación psicológica de la locura. Pero también se aleja de toda teoría que apueste a ver la lengua como algo exterior al sujeto; por ejemplo, en donde aparezca el lenguaje como instrumento, como si este pudiera ser moldeado,

\footnotetext{
${ }^{2}$ Lo que Lacan quiere mostrar con la diferencia del otro con minúscula y el Otro con mayúscula, es que el otro remite al prójimo, pero el Otro remite a un lugar referencial solamente. Cuando yo le digo a mi prójimo que si me ama, yo espero de ese otro ya una respuesta anticipada: sí te amo. Dicha respuesta viene del Otro con mayúscula, lugar de mi Deseo. Pero en la respuesta del Otro no hay certeza; eso podemos verlo en muchos casos en donde alguien termina reclamando en donde creía que había certeza: ¿Por qué haber dicho que me amabas?
} 
manejado o manipulado. Para Lacan, aquello que llamamos sujeto no es otra cosa más que un efecto del lenguaje: el sujeto es efecto de una relación entre un significante con otro significante. ${ }^{3}$ Por lo menos, eso es lo que sostiene en los años sesenta: "Y bien, es simple, es simple y es capital: hace el sujeto. Eso es extremadamente suficiente. Porque, de otro modo, se los pregunto, cómo pueden ustedes justificar la existencia en el mundo de lo que llamamos sujeto" (Lacan, 2018, p. 15).

Puede haber comprensión teniendo cuidado de no querer comprender demasiado pronto. Descartes sostenía que la razón tiende a equivocarse cuando se aventura rápido, aunque el filósofo francés haya caído en ese error, a pesar de él mismo haberlo advertido. Es precisamente este tipo de errores a los que Lacan pone atención. Siempre terminan cuestionado al sujeto que habla. El lenguaje siempre hace agujeros que muestran no un ser sino falta de ser. Heidegger al hablar de posibilidad nos hace ver que también piensa que el ser no es una determinación. Es por eso que el agujero que impone el lenguaje muestra al Deseo, aunque siempre será inconsciente y por lo mismo ambiguo; y es por ese rasgo que no le es transparente al sujeto mismo su Deseo, pero tampoco lo será para sus semejantes. ${ }^{4}$ Hacemos todos los titubeos posibles, nos acercamos y al mismo tiempo damos pasos para atrás, no sabemos qué hacer con lo que queremos. Es posible dar cuenta de esto en los giros del amor; en el poema Palabra y silencio del poeta griego Cavafis dice lo siguiente: "El silencio insensible es grave enfermedad...Hablemos, hablemos - el silencio no es acorde con nosotros, pues a imagen fuimos creados de la palabra". (Cavafis, 1991, p. 559). Pero también en su poema Amor dice lo siguiente: "No se mitiga la desgracia por mucho que hablemos. Pero hay dolores que no se quedan tranquilos en el corazón. Sedientos están de salir por desfogar la queja" (Cavafis, 1991, pp. 595) Podemos ver en ambos poemas el movimiento del Deseo en toda su ambigüedad, y no podemos hacer otra cosa que seguirlo en su movimiento: guardar silencio o hablar demasiado.

\footnotetext{
${ }^{3}$ Es por eso que Lacan escribe parlétre, que debe traducirse como hablaser y no como ser hablante. La idea de que por detrás del lenguaje habría algo que sostiene al lenguaje.

${ }^{4}$ Siempre en el terreno del Deseo nos hacemos las preguntas más incisivas: ¿no sé que quiero? ¿qué quiere él? ¿qué quiere él de mí?
} 
La propuesta de Lacan es entonces dudar de que la razón pueda, de entrada, comprender, a menos que se comprenda callando, lo que aparece en la psicología moderna como un problema constante: El psicólogo habla demasiado. La psicología se vuelve una razón instrumental que determina y legisla lo sano de lo enfermo. La psicología parte de un sujeto que se muestra como comprensible y, por otro lado, de un sujeto que en su cotidianidad aparece sabiendo lo que quiere. Lacan cuestiona ambos momentos e interroga sus efectos.

Ahora bien, el psicoanalista francés, busca más un encuentro con los filósofos que con los psicoanalistas, pues se trata de discutir con ellos sobre un tipo en particular de metafísica que parte de lo Uno. En su Seminario Los nombres del padre, hace hincapié en las caras de este Uno: La Naturaleza, Dios, El Estado, La Razón. Esa metafísica de la cual se aleja por completo es la filosofía eleática (Parménides, Zenón) (Lacan, 2005).

La propia Hannah Arendt, en su libro La promesa de la política, nos muestra que Platón tuvo conciencia de ese Uno y de por qué habría que sostenerlo a toda costa. Su odio a la doxa, a la opinión, la cual llevaba al relativismo: "Platón despreciaba las opiniones y anhelaba criterios absolutos". (Arendt, 2008, p. 45). Freud tampoco pudo salir de esa metafísica, e invocó como punto nodal su teoría paterna, el falo, etc. Y aunque muchos han querido ver en el Otro de Lacan al Uno, el propio Lacan nos dice: “...observen esto, que el Otro en ningún caso es garante de verdad" (Lacan, 2018, p. 19); cosa que para Platón sí lo era; por eso buscaba criterios absolutos. Habría que preguntarnos hasta que punto dicha metafísica pervive en la práctica del psicólogo, aunque quiera por todos los medios buscar enmascarar su práctica bajo un discurso de cientificidad. Al usar en su trabajo con pacientes conceptos que le sirven para legitimar su saber. ${ }^{5}$

Pero hace falta revisar dos cosas: ¿por qué el psicoanálisis debe hacer una lectura de lo unario? Y ¿qué debemos entender en psicoanálisis por sujeto? La noción del sujeto en Lacan es compleja, pues según el año podemos ver distintos momentos de su noción

\footnotetext{
${ }^{5}$ Se puede consultar las clases de Foucault de 1975, el curso Los anormales.
} 
de sujeto. Nos iremos al año de 1975, tiempo en el que Lacan dictaba su seminario "El sinthome"; aparte es ya la época en la que el psicoanalista francés trabaja la topología. Momento en que la noción de sujeto está ligada al nudo borromeo (véase Figura 1) y toma distancia de su definición lingüística. Lacan busca escapar de toda concepción substancial como: individuo, personalidad, persona, etc. Trata de partir de la noción de modelo, con esto se quiere decir, que un modelo, supondría sus nociones con las que se muestra; así que el sujeto es algo que se supone: "Quiero decir que el sujeto como tal es siempre, no solamente doble, sino dividido”. (Lacan, 2006, p. 31) En aquella sesión Lacan muestra a su público que su encuentro con Chosmky fue un discurso de sordos, ya que ambos tenían posturas totalmente opuestas. Chomsky ve el lenguaje como un órgano, muy parecido a una entidad localizable, lo genético. Pensar en términos de substancia es ante todo pensar en una localización y por ende puede ser conceptualizado. Lacan piensa que el lenguaje hace agujero en lo real, con esto quiere dar cuenta que lo real es lo imposible, en la medida que todo lenguaje ex - siste. Con esta palabra lo que busca mostrarnos es que ningún lenguaje tiene su origen y explicación en sí mismo. De ahí que el lenguaje matemático este hecho de innumerables lenguajes que crean axiomas y a la vez teoremas que obligan a la posibilidad de nuevos lenguajes; tómese por ejemplo la lógica: lógica aristotélica, lógica simbólica, lógica de predicados, lógica modal.

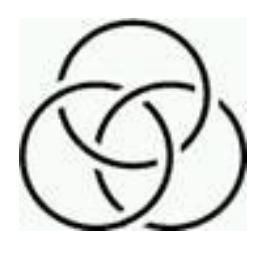

Figura 1.Nudo borromeo

Para Lacan, lo real, simbólico e imaginario son círculos que mantienen su consistencia en la medida que están enlazados: "No hay uno de estos círculos que, al ser envuelto por otro, no resulte envolvente respecto del otro". (Lacan, 2006, p. 35) Con esto Lacan 
muestra que está lejos de todo discurso que tenga la pretensión de dar explicaciones absolutas (Sistema filosófico).

Si volvemos al nudo borromeo nos damos cuenta que ninguno de los tres círculos puede pensarse por separado. Es por eso que el sujeto está agujerado, la consistencia de los tres se halla en que existen cortes para poder mantener el nudo. En pocas palabras, el sujeto lacaniano no está a priori, sino que lo suponemos a partir del nudo. La forma opuesta de pensar el nudo sería la esfera, ya que pone una lógica de un adentro y un afuera, y lo que estaría dentro sería aquello que identificaría como mío, es aquello que me define como yo soy yo (mis pensamientos); a este modelo Lacan se opone de manera contundente. La lógica del nudo es por tanto bidimensional y no tridimensional; en un nudo hay agujeros, pero no hay agujeros adentro y afuera. Con esto Lacan quiere mostrar que el ideal de la auto-referencia sería imaginario. Cada cultura tendría que arreglárselas para que la identificación apareciese, y es ahí que Freud tuvo que construir mitos como el padre de la horda. Por lo tanto, la identificación no tiene su origen en la auto- referencia, sino que le viene del padre que le da al niño un rasgo con el cual se identifique (ideal del yo). Es por eso que en el psicoanálisis no se puede hablar de identidad, madurez, plenitud o unidad. El problema es que al final el propio Freud confundió su mito con el discurso de la ciencia; cuando pensó que en algún momento daríamos cuenta que el Complejo de Edipo se podría sostener en un discurso biológico.

\section{Lo unario versus locura}

Dany-Robert Dufour, en su libro Locura y democracia, desarrolla en dos capítulos un análisis exhaustivo y preciso de lo que entiende por "unario". La auto-referencia nos muestra la frase yo soy yo. Sin embargo, la frase nos dice Dufour es una des-finición, ya que siempre lo que se busca definir con yo no puede ser definido con la misma palabra la cual se busca definir. Nos introduce en un juego al infinito. El diálogo se desenvuelve a partir de un texto de Benveniste, nos referimos a su ya famoso libro Problemas de 
lingüística general $I$, en un capítulo pequeño, pero complejo, que se llama: "De la subjetividad en el lenguaje". En ese trabajo quiere el lingüista francés hacer una crítica al dualismo que hace ver al hombre y al lenguaje como dos entidades contrapuestas, de la misma manera que se hace entre naturaleza y cultura, y también entre individuo y sociedad. La relación entre yo y tú no se trata de entes. No hay yo si no hay tú, pero como se había mencionado, no se trata de entidades sino se actos del discurso (formas lingüísticas) que se mueven de una manera circular: yo puede ser tú y tú puede ser yo según el movimiento en el acto discursivo. Desde la perspectiva de Benveniste no puede haber sujeto si no hay una lengua: Una lengua sin expresión de la persona no se concibe (Benveniste, 2007, p. 182).

Podríamos decir que la lengua es una abstracción, pero es el sujeto del acto discursivo quien se apropia de esa lengua al decir yo. Yo remite a mí en tanto que hablo. Eso es para Benveniste el fundamento de lo que llamamos subjetividad. De ahí al uso de las deixis, que introducen la dimensión del tiempo en nuestro discurso: "Pero cuidémonos: no hay otro criterio ni otra expresión para indicar "el tiempo en que se está que tomarlo como "el tiempo en que se habla" (Benveniste, 2007, p. 183).

Pero para Dufour no queda clara la propuesta de Benveniste, ya que ésta nos muestra dos yo, en el que el primero es el sujeto de la enunciación y el segundo sería el significante; como se puede ver ya nos encontramos en algo propiamente del orden de lo unario. Pues el primero yo es también un significante, sino lo fuera estaríamos de nueva cuenta en el dualismo hombre-lenguaje que critica el lingüista al principio del capítulo: "... decir yo es lo que desencadena la posibilidad de ser yo pero además ser yo es lo que permite la posibilidad de decir yo" (Dufour, 2002, p. 64). Con esto nos hemos acercado a lo que Dufour piensa con el termino unario, pero ahora falta ver su relación, si se puede decir, con una nueva forma de entender la locura.

Antes de encontrar la relación de lo unario con la locura es muy importante decir que Dufour no toma el concepto de locura de la psicología, o específicamente de la psicopatología. Mas bien su concepto de locura parte de un discurso que tiende a crear paralogismos y que lo ubica en casi todas las culturas; con esto quiero decir que todo 
discurso hace posible lo unario. En el caso de México, en los últimos años se puede identificar lo unario en relación a un incremento de la violencia que nunca se había visto. Así que, si antes un crimen se buscaba ocultar, ahora se cuelga a alguien en un puente peatonal para que a través de ese muerto se comunique algo a las autoridades 0 a otro grupo criminal. Estamos en el juego ya no del ocultar, sino en el de desocultar. Aquello que inspiró a muchos literatos del Thriller con Sherlock Holmes en un contexto mexicano no opera: Ahora ya no hay que buscar a los muertos, ya que estos aparecen en carreteras o colgados, o también aparece otra forma que es la desaparición de los cuerpos a través de ácidos, de ser quemados y tirados en fosas clandestinas, o también descuartizados hasta el punto más radical de no poder reconocer un cuerpo. La famosa lógica de buscar pistas para llegar a encontrar al muerto y al asesino se disuelve de una manera trágica; por ejemplo, véase este titular del periódico BBC Mundo: "La Procuraduría (fiscalía) General de Justicia (PGJ) del estado de Nuevo León, en el noreste de México, analiza más de 30.000 restos humanos localizados en un rancho del municipio de Salinas Victoria" (Nájar, 2015). La noticia muestra el nivel de violencia, pero también nos muestra que estos grupos buscan desaparecer de manera radical a sus víctimas, hasta el punto de no poder identificarlas. Ahora bien, las investigaciones en este país son deficientes a la hora de buscar a los responsables: inculpando a gente inocente; aparte de que los obligan a declarar a través de actos de tortura y con procesos corruptos. Lo que hace que sea imposible encontrar a los responsables y que se identifiquen los cuerpos, así como saber cuánta gente en realidad ha desaparecido. No se cuenta hasta el día de hoy estadísticas certeras sobre los desaparecidos, ya que las que da el gobierno mexicano no son confiables, ya que los gobiernos han mostrado, independientemente del partido político, falta de voluntad para mostrar una realidad que ya nos ha rebasado.

La mayoría de las víctimas padecen violencia no nada más por parte del crimen organizado, sino de policías, militares o ministerios públicos. En el informe de Human Rights Watch del año 2014 dice algo acerca de la tortura en México:

"Es común que en México se practiquen torturas para obtener información y confesiones bajo coacción. En general, las torturas se aplican durante el período desde que las 
víctimas son detenidas arbitrariamente hasta el momento en que son puestas a disposición de agentes del Ministerio Público, y en el cual a menudo son mantenidas incomunicadas en bases militares u otros centros de detención clandestinos. Las tácticas más frecuentes incluyen golpizas, simulacros de ahogamiento, descargas eléctricas y tortura sexual. Son muchos los jueces que aún admiten confesiones obtenidas mediante tortura, a pesar de que existe una prohibición constitucional contra este tipo de prueba".

Con lo que hemos mencionado, podemos ver la inversión de valores. Lo unario nos muestra que la población sufre de violencia de quien debería esperar la protección y atención. Violencia que se disemina en muchos actores de gobierno, como se puede apreciar en la cita. Hasta el punto que la gente en muchas circunstancias decide mejor no dar aviso a las autoridades y, por tal motivo, prefieren vivir su tragedia en el anonimato y en el silencio absoluto. De ahí que muchas de las estadísticas no tengamos datos certeros de cuántos desaparecidos hay en este país. ${ }^{6}$

\section{Conclusión}

En las democracias modernas, la locura y lo unario se ocultan en la medida que se sostenga la idea de auto-referencia y de la soberanía de un yo encerrado en sí mismo. Este ideal de la razón autónoma choca con innumerables experiencias en donde el sujeto se ve cuestionado en su vida cotidiana. Tanto la propuesta de un sujeto que piensa en el sentido kantiano (moral) o en la de un sujeto que sabe moverse en su mundo —en su hacer- en el sentido heideggeriano; no nos permiten sacar consecuencias de lo unario. Aunque nos permiten revelarlo en su dimensión más cómica, lo que puede ser a su vez

\footnotetext{
${ }^{6}$ Hace poco tiempo se convirtió en algo viral un video que circulo por internet, en donde el grupo terrorista Estado Islámico (Isis) amenazaba a los países aliados de Estados Unidos. En dichas amenazas figuraba México. Pues muchos jóvenes en tono de broma twitearon que se sentían protegidos por que el Chapo nos protegería. Broma que muestra el nivel de descalificación que tienen tanto el gobierno en turno, como todos los partidos y clase política de este país. Es clara la inversión de valores sobre los buenos y los malos.
} 
también trágico. ${ }^{7}$ Incluso podemos dar cuenta también de lo unario cuando un policía puede ser a su vez un sicario o cuando un gobernador puede ser quien robe el erario público. También podemos dar cuenta de lo unario cuando una sociedad pone de modelo a algún narcotraficante. Así, parte de la población idealiza y padece al mismo tiempo la inversión. Lo unario nos hace reconocer que la tesis freudiana de que la neurosis es lo que permite hacer lazo con los otros, en nuestra época, parece ya no decir casi nada. Lo unario nos muestra que en este juego del lenguaje, la locura es lo que hace lazo con los otros. En lo unario es imposible encontrar una certeza que nos lleve a pensar dualismos como bueno y malo, o racional e irracional. Estas categorías se confunden hasta el punto que las personas no pueden dar cuenta de la dinámica.

La aportación que nos hace Dany Robert-Dufour es de mucha importancia para dar cuenta de lo unario en el trabajo clínico. El psicoanalista debe seguir la regla freudiana del caso por caso, y es a partir de esta regla fundamental que el analista debe poner atención al malestar subjetivo de su tiempo, el cual se devela en el diván.

\footnotetext{
${ }^{7}$ Circuló una noticia en México en la que jóvenes pertenecientes a un partido político, que ha sido considerado de derecha, creó una organización de nombre "Movimiento Nacionalista Mexicano del Trabajo", cuyos objetivos son: proteger a la familia tradicional, así como a la iglesia católica y a los empresarios del país, este movimiento parte de una ideología Nazi (revisionismo). Quien representa a esta organización del partido es Juan Barrera Espinosa, consejero estatal juvenil del Partido Acción Nacional (PAN). La mayoría de sus adeptos al ser convocados a una reunión para conmemorar el aniversario 125 de Adolf Hitler, fueron fotografiados emulando a este: Lo risible es que en su mayoría todos son morenos, situación que hace ver que si Hitler siguiera vivo no estaría orgulloso de congregar a estos jóvenes; hay que decir que a esta noticia se le conoció con el nombre de "morenazis".
} 


\section{Referencias}

Arendt, H., (2008), La promesa de la política. Barcelona, España: Austral.

Aristóteles, (2007), Metafísica. Barcelona, España: Gredos

Benveniste, É., (2007), Problemas de lingüística general I. Ciudad de México, México: Siglo XXI.

Cavafis, C., (1991), Obra poética completa, Edición bilingüe de Alfonso Silván Rodríguez. Madrid, España: Ediciones La Palma.

Descartes, R., (2014a), Reglas para la dirección del espíritu. Madrid, España: Gredos.

Descartes, R., (2014b), Discurso del método. Madrid, España: Gredos.

Descartes, R., (2014c), Las pasiones del alma. Madrid, España: Gredos

Dufour, D.R., (2002), Locura y democracia. Ciudad de México, México: FCE.

Fromm, E., (1985), El miedo a la libertad. Barcelona, España: Planeta.

Heidegger, M., (2009), Ser y tiempo. Madrid, España: Trotta.

Hernández Vega, R., (1991), Análisis de dos discursos de Kant sobre la sociedad civil. Ciudad de México, México: UNAM.

Human Rights Watch. (2014). Informe Mundial 2014: México. Eventos de 2013. Recuperado de https://www.hrw.org/es/world-report/2014/country-chapters/260113

Kant, I., (2004), Filosofía de la historia/ ¿Qué es la llustración? Buenos Aires, Argentina: Caronte Filosofía.

Lacan, J., (2018), Discurso a los psiquiatras. [ebook] Buenos Aires: ELP. Available at: http://e-dicioneselp.net/images/secciones/novedades/L-67-11-10.pdf [Accessed 15 Apr. 2015].

Lacan, J., (2006), Seminario 23, El sinthome. Buenos Aires, Argentina: Paidós.

Lacan, J., (2003), Escritos 2. Ciudad de México, México: Siglo XXI.

Lacan, J., (2005), De los nombres del padre. Buenos Aires, Argentina: Paidós.

Nájar, A. (1 de septiembre de 2015). Revelan hallazgo de miles de fragmentos humanos en rancho de México. BBC Mundo. Recuperado de http://www.bbc.com/mundo/noticias/2015/09/150901_mexico_restos_humanos_nuevo_leon_an 